\title{
ESTIMATING THE PROPERTIES OF A FINE AGGREGATE FIBRE REINFORCED CEMENTITIOUS COMPOSITE USING NON-DESTRUCTIVE METHODS
}

\author{
Wiesława GŁODKOWSKA ${ }^{1}$ (D), Janusz KOBAKA ${ }^{2 *}$ (D) \\ ${ }^{1}$ Department of Concrete Structures and Concrete Technology, Faculty of Civil Engineering, \\ Environmental and Geodetic Sciences, Koszalin University of Technology, Koszalin, Poland \\ ${ }^{2}$ Department of Construction and Building Materials, Faculty of Civil Engineering, \\ Environmental and Geodetic Sciences, Koszalin University of Technology, Koszalin, Poland
}

Received 29 May 2018; accepted 03 September 2018

\begin{abstract}
The paper proposes a method of estimating the properties of a fine aggregate steel fibre reinforced cementitious composite using non-destructive methods. Two methods were selected to identify the properties of such a composite. One of them uses electromagnetic induction in order to estimate the content of steel fibres dispersed in the composite space, while the other is based on the determination of ultrasonic wave velocity propagating through the composite. Having defined correlations between the properties of the fibre reinforced composite and non-destructive testing parameters, regression equations were determined. Seven relationships between properties of fibre reinforced composite as the dependent variables and two independent variables, i.e.: amperage and ultrasonic wave velocity, were established. Knowing the amperage and the ultrasonic wave velocity, the basic properties of the fibre reinforced composite can be determined from the regression equations in a non-destructive manner. In order to verify the equations, three plates with different amounts of steel fibres were made in field under natural conditions, and next subjected to non-destructive tests. The tests showed good compatibility between the experimental results and those of calculations, which indicates the correctness of the formulated equations.
\end{abstract}

Keywords: fibre reinforced composite, non-destructive testing, properties, SFRC, waste sand, concrete.

\section{Introduction}

Concrete is currently the most commonly applied building material and, over the recent years, a dynamic increase in concrete engineering has been observed throughout the world. Because of the advantages it offers, such as its general availability and relatively low costs of production, concrete is widely applied in the residential and industrial construction sector.

Modern-day structures pose a difficult task out for engineers, connected with fulfilling the requirements of limit states (LSs) in very diverse conditions of static and dynamic impacts. Unfortunately, concrete is a brittle material, which becomes more fragile along with increasing loads. Its low tensile strength and susceptibility to crack propagation has been forcing researchers to seek out new types of concrete, the physical and mechanical parameters of which will meet the current requirements.
Strength and serviceability requirements for construction materials have led to the mixture of the mineral composite, i.e. cement, aggregate and water, becoming a relic of technology. Currently, the composition of the mixture is enriched with various admixtures (plasticizers, superplasticizers, air entraining admixtures or ones delaying or accelerating hardening time) and additives (silica dust, blast furnace slag, fly ash). In an effort to increase tensile strength of such a composite, scattered reinforcement in the form of fibres, e.g. steel, glass, polypropylene, polyethylene or carbon, are also introduced. In such a way, we obtain the so-called fibre reinforced cementitious composite (FRCC).

Currently, the popularity of fibre reinforced concrete, generally referred to as fibre reinforced composite, is continuously increasing, both on a national and global level.

*Corresponding author. E-mail: janusz.kobaka@tu.koszalin.pl 
In certain applications, they serve as an alternative to ordinary concrete. The most important advantages of FRCC include: higher tensile strength in the early stages of curing compared to ordinary concrete, higher axial tensile strength (Lee 2018; Yazici et al. 2007) and flexural tensile strength (Kim et al. 2016) or splitting tensile strength (Balanji et al. 2017; Yap et al. 2016), high dynamic resistance (Li et al. 2016; Teng et al. 2008; Wang et al. 2008), limited crack propagation in structural elements (Uygunoğlu 2008), better reaction to destruction (Wang et al. 2010) (destruction does not occur abruptly), the possibility of reducing traditional reinforcement, or high heat resistance (Sukontasukkul et al. 2010). The fundamental drawbacks of FRCC are mainly: relatively high cost of fibres, worsened workability along with increased fibre content, and the lack of guidelines for designing elements made of FRCC (Benoa, Hilara 2013).

Due to good physical and mechanical parameters of FRCC, they are currently applied for creating various structural elements, such as foundation slabs, floor slabs (Gholamhoseini et al. 2016), columns (Bae et al. 2018), beams (Mahmod et al. 2018), thin-shell structures, industrial flooring, elements of bridges (Zhang, Dias-da-Costa 2017), tunnels (Meng et al. 2016), elements for reinforcing mining excavations, and even in structures at risk of seismic impact as well as for preparing structural elements of nuclear power plants.

Considering such a broad spectrum of application for FRCC, the lack of a fast, non-invasive and effective method of assessing its properties can be noticed. Moreover, the applied methods of assessing the properties of a FRC on standardized specimens do not allow for an accurate assessment of the distribution of the values of its properties within the elements and structure. Proper monitoring of the quality of the material in a structure involves the assessment of its properties and uniformity using methods which do not result in damage to the analysed element.

An important element in the diagnosis of construction elements made of FRCC is to determine the distribution of fibres in the volume of the composite which are randomly arranged. Some of the non-destructive methods allow for such evaluation as electrical resistivity measurements (Lataste et al. 2008), computed tomography (Pinter et al. 2018), analysis of the image of cross-sections of the diagnosed element which the authors presented in the paper (Głodkowska, Kobaka 2012). The distribution of fibres in the FRCC space affects its properties to a large extent (Lusis et al. 2017). It is shaped by a number of factors such as: the matrix properties (i.e. consistency of the mixture, the size of the aggregate grains), the process of mixing, forming and compaction. During the mixing and forming phase, the fibres tend to disperse in the composite space and they are given a spatial orientation. During the compaction of the FRCC mixture the fibres partially settle (Głodkowska, Kobaka 2012).

The article proposes a means of determining the properties of a fine aggregate FRCC using non-destructive methods. Two methods were selected for identifying the properties of such a composite on the basis of literature studies (Hoła, Schabowicz 2010; Meyer 2009). One of them uses electromagnetic induction to assess the level fibre content in the composite; the other is based on establishing ultrasonic wave velocity in composite space. The correlation of results obtained using non-destructive methods with corresponding values of composite features determined experimentally made it possible to establish regression equations. In these equations, the independent variables are amperage $(I)$ and ultrasonic wave velocity $(V)$. The dependant variable is a property of a fine aggregate FRCC. The study was carried out for different steel fibre volume fractions in a fine aggregate FRCC.

\section{Materials and sample elements}

Post-glacial sand obtained following the process of hydroclassification from the region of West Pomerania was used to make the sample elements. Applying such sand is consistent with the global tendency connected with environmental sustainability (Meyer 2009; Hendriks, Janssen 2003; Soares et al. 2014; Ulsen et al. 2013). A similar situation, with excessive sand fractions, may be observed in other areas of the world, e.g. in the Middle East or North Africa (Al-Harthy et al. 2007). Figure 1 presents sieve curves of sand indicated by various authors. The results do not differ significantly despite the fact that the sands derived from various aggregate quarries found in the area of northern Poland. This proves that the deposits were formed in the same period and are probably post-glacial and fluvioglacial sediments.

Another component was Portland cement CEM II/A-V 42.5R, silica dust and a superplasticizer containing pozzolana. Reinforcement comprised hook-shaped steel fibres with a slenderness ratio of $\lambda=l_{f} / d_{f}=62.5(l=50 \mathrm{~mm}$, $d=0.8 \mathrm{~mm}$ ). The characteristics of the steel fibres used are discussed in Domski and Głodkowska (2017). The composition of the matrix was modified by the addition of silica dust as well as a superplasticizer allowing for a $\mathrm{w} / \mathrm{c}=0.38$ ratio to be obtained. The content of steel fibres

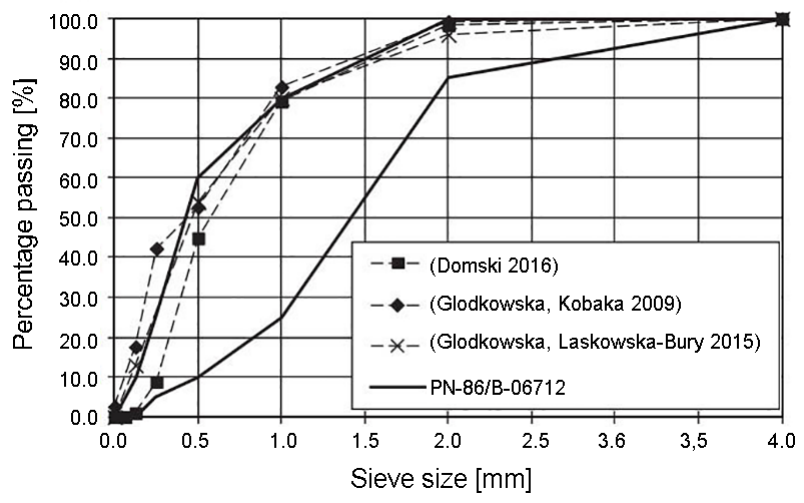

Figure 1. Grading curve of used aggregate and grading curves of other Pomeranian aggregates used in different research programmes (Domski, Głodkowska 2017; Domski 2016; Głodkowska, Kobaka 2009; Głodkowska, Laskowska-Bury 2015) 
$\left(V_{f}\right)$, which were added in doses of $0.5 \%$ of the FRCC volume up to $2.5 \%$, was assumed as the varying component of the FRCC. Fibres in the FRCC mixture were distributed in a random manner. Compressive strength $\left(f_{c, \text { cube }}\right)$, splitting tensile strength $\left(f_{t, s p l}\right)$, apparent density $(\rho)$, and dynamic modulus of elasticity tests $\left(E_{d}\right)$ of the fine aggregate FRCC were carried out on cubic specimens with sides measuring $150 \mathrm{~mm}$. Shrinkage $\left(\varepsilon_{s}\right)$ was determined on beams measuring $100 \times 100 \times 400 \mathrm{~mm}$. Tests for dynamic shear modulus $\left(G_{d}\right)$ were carried out on beams measuring $100 \times 100 \times 500 \mathrm{~mm}$. Abrasion resistance $(S)$ of the FRCC was tested on cubic specimens with sides measuring $71 \mathrm{~mm}$.

The number of specimens necessary for determining the average statistical value of the analysed property was indicated based on the statistical analysis of results of preliminary studies at $v=10 \%$ tolerance and $\alpha=0.10$ level of significance.

\section{Characterization and testing}

Strength $f_{c, \text { cube }}$ was determined in accordance with EN 12390-3 (2009), and strength $f_{t, s p l}$ acc. to EN 12390-6 (2009). Apparent density $\rho$ was indicated in accordance with EN 12390-7 (2000) guidelines, while the dynamic modulus of elasticity Ed was defined on the basis of the analysis of ultrasonic wave velocity in accordance with. Resistance to abrasion $S$ of the composite was determined according to guidelines given in PN-84/B-04111 (1984). The shrinkage strain $\varepsilon s$ of the composite in time t was monitored until it had reached stabilization (1 year) at a relative humidity of $50 \pm 3 \%$ and temperature of $20 \pm 2{ }^{\circ} \mathrm{C}$. The dynamic sheer modulus $G_{d}$ was determined on the basis of torsional vibrations of the beam (Figure 2) on the basis of relationship (1) (Weiler, Grosse 1995):

$$
G_{d}=4 R m l f_{\text {tors }}^{2} /\left(A k_{i}^{2}\right),
$$

where $R$ - coefficient dependant on the dimensions of the beam cross section $b$ and $h$ :

$$
R=(b / h+h / b) /\left(4 b / h-2.52(b / h)^{2}+0.21(b / h)^{6}\right),
$$

$k_{i}$ - coefficient dependant on the type of vibrations (for basic frequency $k=1)[-] ; f_{\text {tors }}$ - frequency of natural vibrations $[\mathrm{Hz}] ; A$ - cross-sectional area of beam $[\mathrm{mm}]$; $h$ - height of beam cross-section [mm]; $m$ - mass of beam $[\mathrm{kg}] ;$ l - length of beam [mm].

Upon inducing torsional vibrations by impact with a steel ball, the signal from the sensor (Figure 2) was transmitted to a SVAN 910A noise and vibration analyser. The torsional vibration frequency was indicated in this analyser based on Fourier's analysis.

The remaining non-destructive tests were carried out using a reinforcement detector (accuracy of $0.2 \mathrm{~mA}$ ) and ultrasonic concrete tester - betonoscope (accuracy of $0.1 \mathrm{~ms}$ ) with a measurement frequency of $54 \mathrm{kHz}$. The first of these methods (using reinforcement detector), based on electromagnetic induction, was used to assess the steel

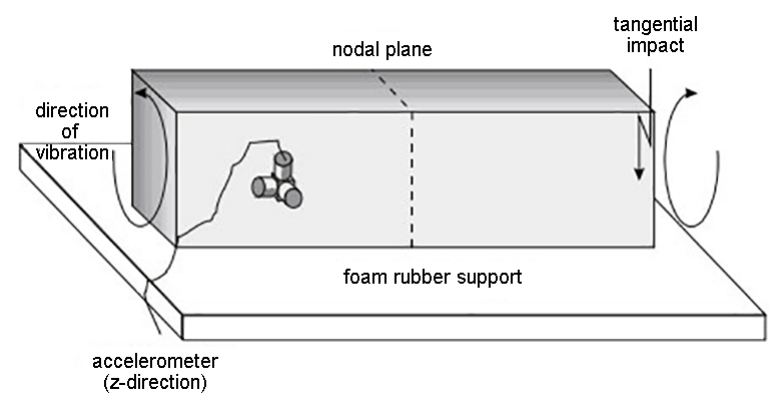

Figure 2. Test setup for torsional vibrations (Weiler, Grosse 1995)

fibre reinforcement content in the analysed FRCC and indicate the correlation of its selected characteristics and the induced amperage $I$. The second of these methods (using betonoscope) was applied for determining the correlation of FRCC characteristics and ultrasonic wave velocity $V$ (Hoła, Schabowicz 2010; Meyer 2009).

\section{Test results and analysis}

Non-destructive studies, accompanying all destructive one-time tests, allowed for determining the relationships between them. Figures 3-6 present the correlation between strength $f_{c, \text { cube }}$, density $\rho$, modulus $E_{d}$, resistance to abrasion $S$ and amperage $I$. Strength $f_{c, \text { cube }}$ (Figure 3 ) and density $\rho$ (Figure 4 ) increase along with an increase in amperage $I$, though this is not a straight-line relationship. For high values of amperage $(I>3 \mathrm{~mA})$, which correspond to fibre content of $V_{f}>1.5 \%$ in relation to the volume of the FRCC, the increase in strength $f_{c, \text { cube }}$ and density $\rho$ is insignificant. This is caused by the aeration of the FRCC mixture by high fibre volume fraction during mixing (Maidl 1995). The value of modulus $E_{d}$ increases along with an increase in amperage $I$, though above the value of $I=2.9 \mathrm{~mA}$, which corresponds to $1.8 \%$ fibre volume fracture, the value of the modulus decreases (Figure 5). This is also caused by the aeration of the FRCC mixture. The fibre-free composite was characterized by a $10 \%$ lower dynamic modulus of elasticity than the composite with fibre volume fraction $V_{f}=1.5 \%$. The highest abrasion resistance is revealed by the FRCC at an amperage of $I=2.2 \mathrm{~mA}$ (Figure 6) which corresponds to a fiber content of $1.4 \%$. In the case of shrinkage $S$, the increase in amperage $I$, which corresponds to increasing fibre volume fraction in the FRCC, is accompanied by limited shrinkage strain.

The functions describing the correlation between strength $f_{c, \text { cube }}$ and fibre volume fraction $V_{f}$ as well as amperage $I$ (Figures 3 and 7) are characterized by a similar course; strength $f_{c, \text { cube }}$ increases in a non-linear manner along with an increase in fibres $V_{f}$ and amperage $I$. Thus, the dependence of fibre volume fraction up to $V_{f}=1.5 \%$ in a composite having a significant influence on an increase in strength $f_{c, \text { cube }}$. Above this value of fibre volume, an insignificant increase in strength $f_{c, \text { cube }}$ is observed. Moreover, the fact that the courses of functions shown in 




Figure 3. Correlation between compressive strength $f_{c, \text { cube }}$ and the amperage $I$

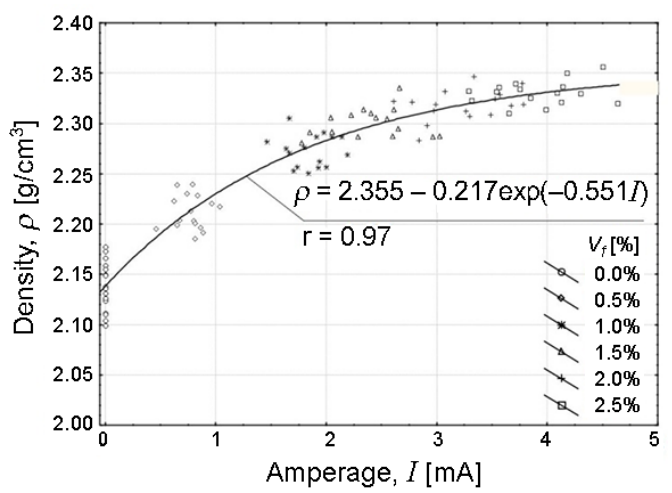

Figure 4. Correlation between density $\rho$ and the amperage $I$

Figures 3 and 7 are similar demonstrates the possibility of applying the method of electromagnetic induction for assessing the content of steel fibre reinforcement in FRCC. A similar correlation was also obtained for the remaining properties of the FRCC.

In three cases, two curves were used to describe the relationship between strength $f_{c \text {, cube }}$, density $\rho$, modulus $E_{d}$ and wave velocity $V$ (Figures 8-10). Statistical analysis showed that the results of the studies described by the two curves do not belong to the same population. Figures 8-10 illustrate that, following an increase in fibre volume fraction to $1.5 \%$, a significant increase in strength $f_{c, \text { cube }}$ and density $\rho$, and modulus $E_{d}$ of the composite occur along with an increase in wave velocity $V$. Above $1.5 \%$ fibre volume fraction, the increase in strength $f_{c, \text { cube }}$ and density



Figure 5. Correlation between modulus $E_{d}$ and the amperage $I$

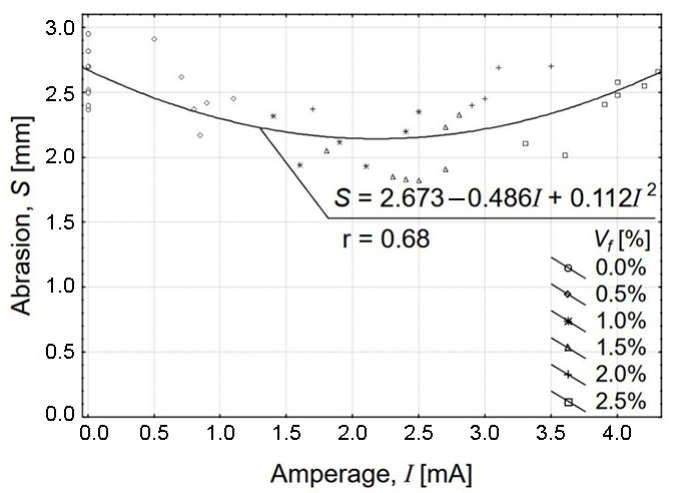

Figure 6. Correlation between abrasion $S$ and the amperage $I$

$\rho$ is insignificant, while the value of modulus $E_{d}$ decreases, along with decreasing wave velocity. Moreover, it was observed that the resistance to abrasion $S$ of the composite increases along with an increase in wave velocity $V$ (Figure 11).

Having defined the correlations of selected properties of the FRCC and parameters of non-destructive tests ( $V$ and $I$ ), regression equations $y$ (property of the FRCC) in relation to $x$ and $z$ (amperage $I$ and wave velocity $V$ ) were indicated from the analysis - compare Figures $12-15$, as well as Eqns (3)-(9).

With the knowledge of wave velocity $V$ and amperage I from Eqns (3)-(9), the basic properties of the fine aggregate composite under study can be determined.

$$
\begin{cases}f_{c, \text { cube }}=-164.93+53.29 \exp (-0.0493 V /(1.792+I)) ; & r=0.93 ; \\ f_{t, \text { spl }}=2.241 V-6.527 \exp (-0.544 I) ; & r=0.97 ; \\ E_{d}=-664.3+300.1 V-31.74 V^{2}+I(1.936-0.259 I) ; & r=0.98 ; \\ S=I(-0.299+0.071 I)+V(2.854-0.527 V) ; & r=0.77 ; \\ \varepsilon_{s}=9.554\left(1-\exp \left(-2.264 \mathrm{t}^{0.098}\right)\right)-V(4.171+0.510 V)-0.029 I ; & r=0.97 ; \\ \rho=-26.03+V(12.83-1.45 V)-0.210 \exp (-0.603 I) ; & r=0.97 ; \\ G_{d}=-61.74+V(34.78-3.79 V)+I(0.590-0.138 I) ; & r=0.80 .\end{cases}
$$




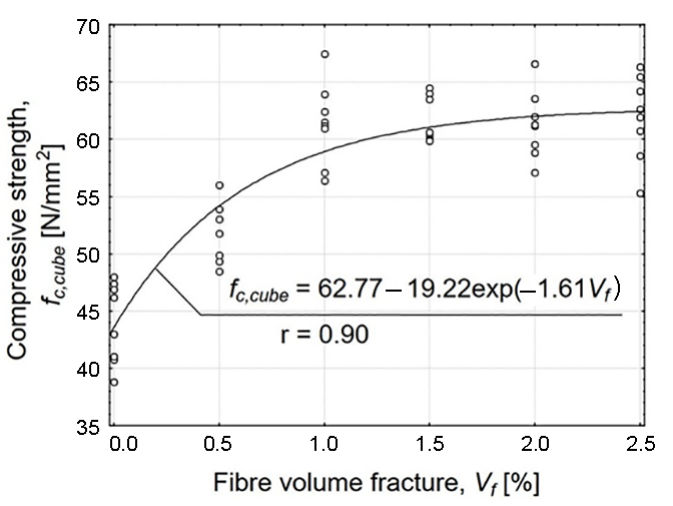

Figure 7. Correlation between $f_{c, \text { cube }}$ strength of tested composite and fibre volume fraction $V_{f}$

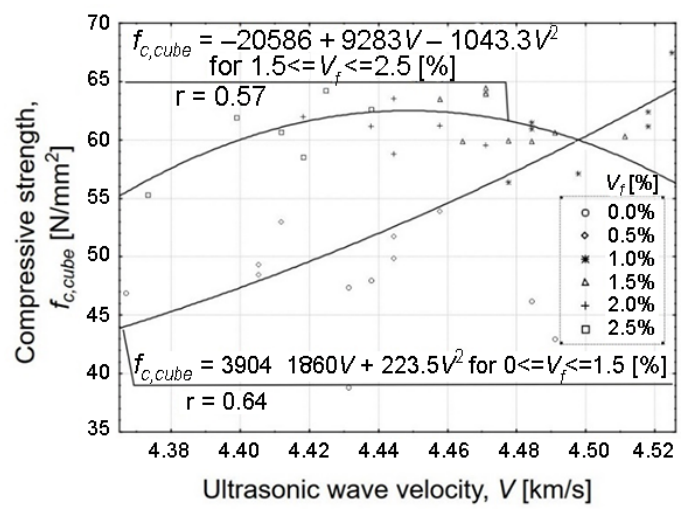

Figure 8. Correlation between $f_{c, c u b e}$ strength of tested composite and the ultrasonic wave velocity $V$

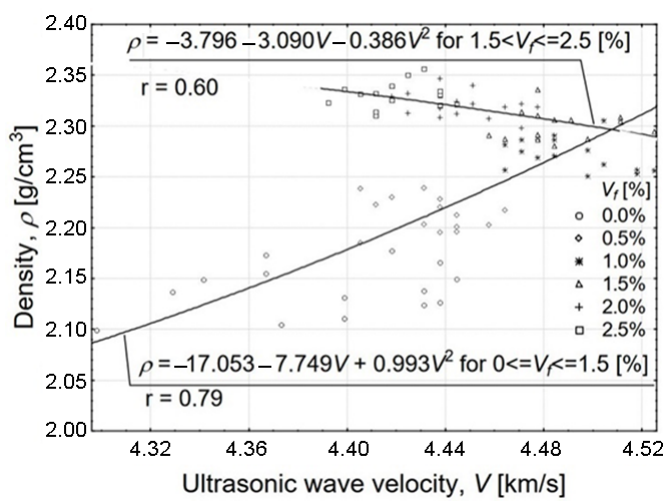

Figure 9. Correlation between density $\rho$ of tested composite and the ultrasonic wave velocity $V$

\section{Practical verification}

In order to verify the system of Eqns (3)-(9), three slabs of varying steel fibre volume fractions, i.e. $0 \%, 1 \%$ and $2.5 \%$, were prepared in field. After approximately three years of storing the sample element under natural conditions, they were subjected to non-destructive and destructive tests. Non-destructive tests have shown that for fibre volume fractions: $0 \%, 1 \%, 2.5 \%$ mean values of inducted current were respectively: $0 \mathrm{~mA}, 1.2 \mathrm{~mA}, 2.8 \mathrm{~mA}$ and mean val-

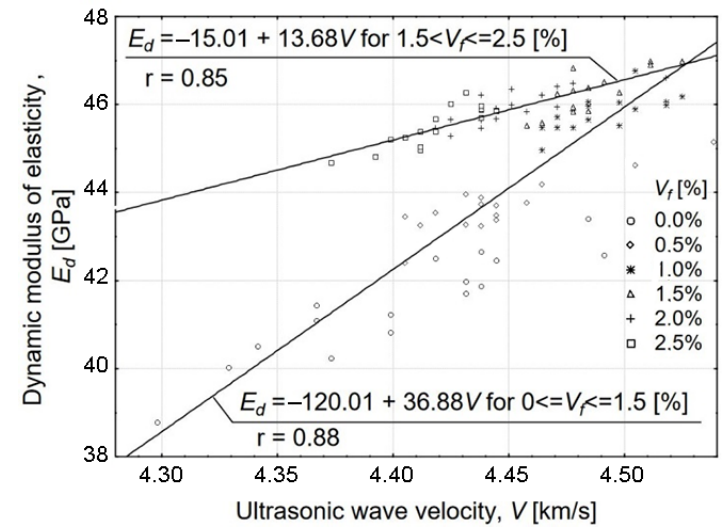

Figure 10. Correlation between modulus $E_{d}$ of tested composite and the ultrasonic wave velocity $V$

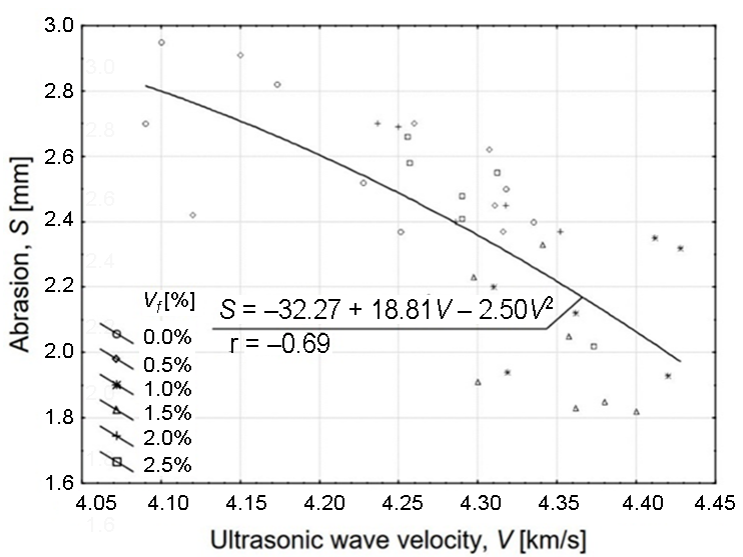

Figure 11. Correlation between abrasion $S$ of tested composite and the ultrasonic wave velocity $V$

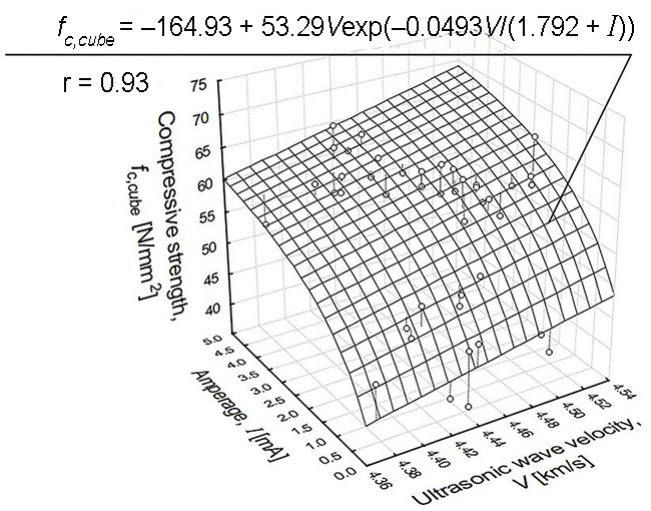

Figure 12. Exemplary correlation between $f_{c, \text { cube }}$ strength and: ultrasonic wave velocity $V$, amperage $I$

ues of ultrasound propagation time: $4.48 \mathrm{~km} / \mathrm{s}, 4.54 \mathrm{~km} / \mathrm{a}$, $4.50 \mathrm{~km} / \mathrm{s}$.

Sample results of studies on the properties of the FRCC obtained using non-destructive tests and calculated using Eqns (3)-(9) have been compiled in Figures 16-19. Analysis of the obtained test results showed that the differences between the values gained in the tests and calculated values were within the range from $2 \%$ for dynamic modulus of elasticity up to $9 \%$ for splitting tensile strength and were statistically insignificant. On this basis, a good agreement 


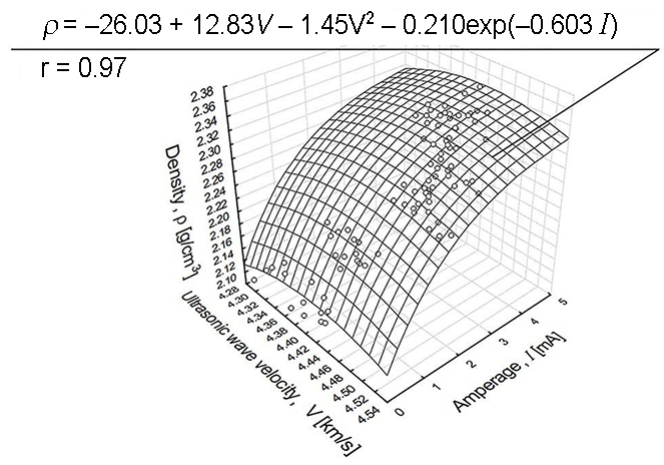

Figure 13. Exemplary correlation between density $\rho$ of tested composite and: ultrasonic wave velocity $V$, amperage $I$

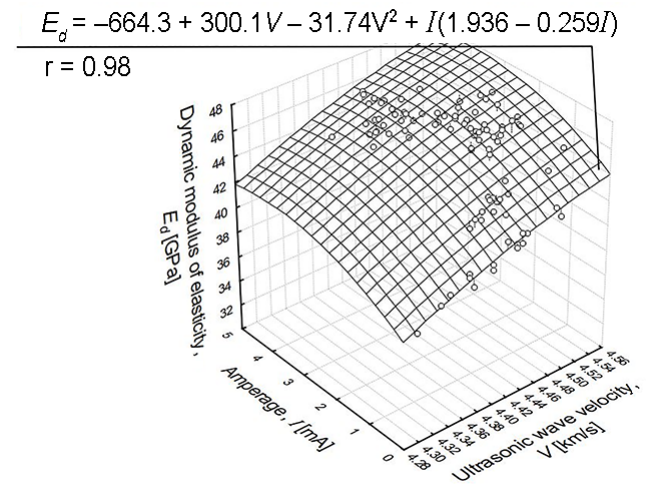

Figure 14. Exemplary correlation between modulus $E_{d}$ and: ultrasonic wave velocity $V$, amperage $I$

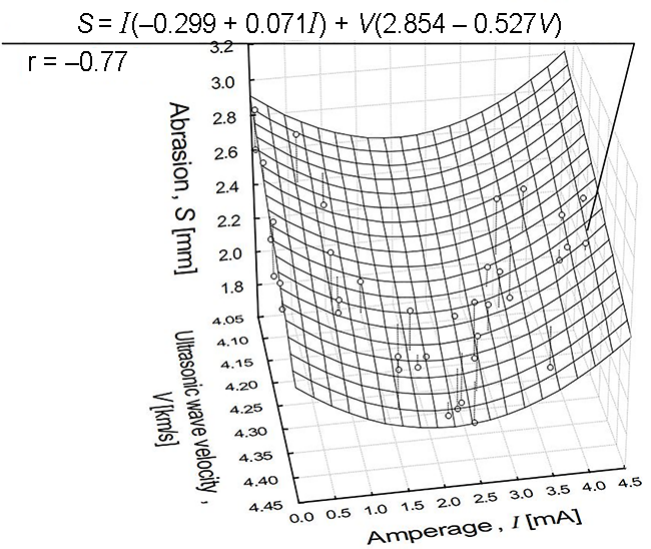

Figure 15. Exemplary correlation between abrasion $S$ and: ultrasonic wave velocity $V$, amperage $I$

between the experiment and the calculations was found which indicates the correctness of formulated equations.

\section{Conclusions}

1. The method of electromagnetic induction along with a method based on ultrasonic wave velocity can be applied to estimate the properties of a fine aggregate steel fibre reinforced cementitious composite (FRCC).

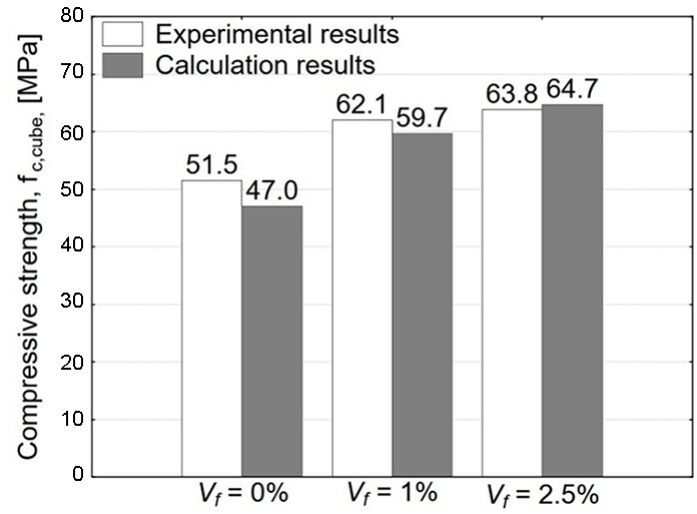

Figure 16. Comparison of values obtained in research and in calculations: $f_{c, \text { cube }}$ strength of tested FRCC

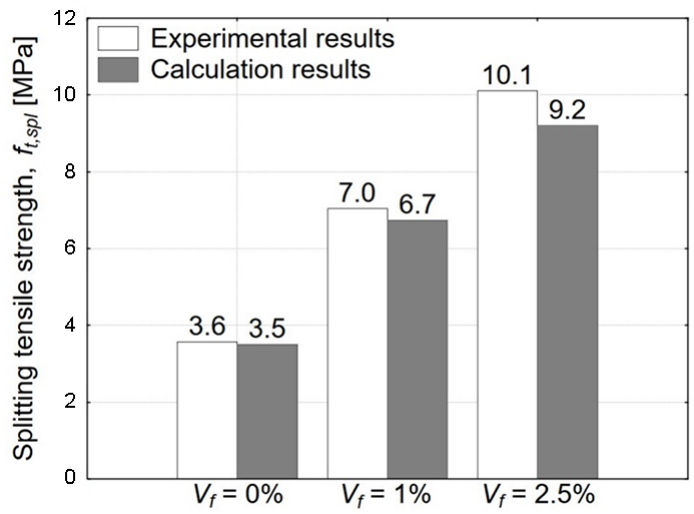

Figure 17. Comparison of values obtained in research and in calculations: splitting tensile strength $f_{t, s p l}$ of tested FRCC

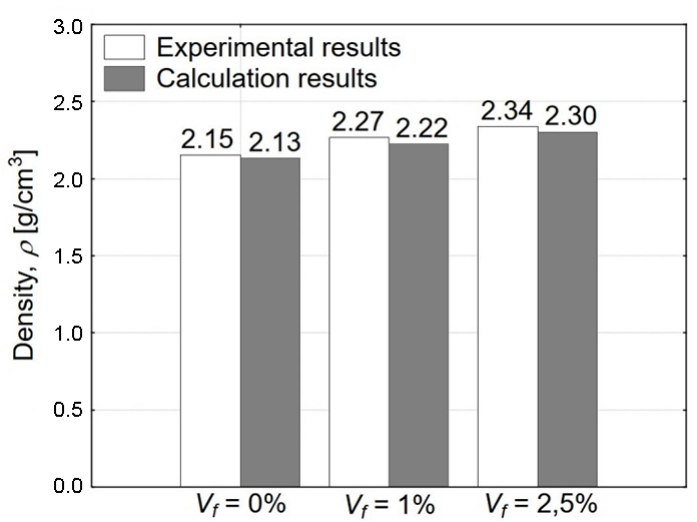

Figure 18. Comparison of values obtained in research and in calculations: density $\rho$ of tested FRCC

2. The proposed regression equations will enable the non-destructive identification of properties of a fine aggregate FRCC. These relationships may also prove useful in determining the properties of other materials similar in terms of the composition of the mixture and fibre type.

3. The tested FRCC based on waste sands containing the steel fibre volume fraction $1-1.5 \%$ is characterized by the best physical and mechanical properties. Fibre addition above $1.5 \%$ because of the properties and the price 


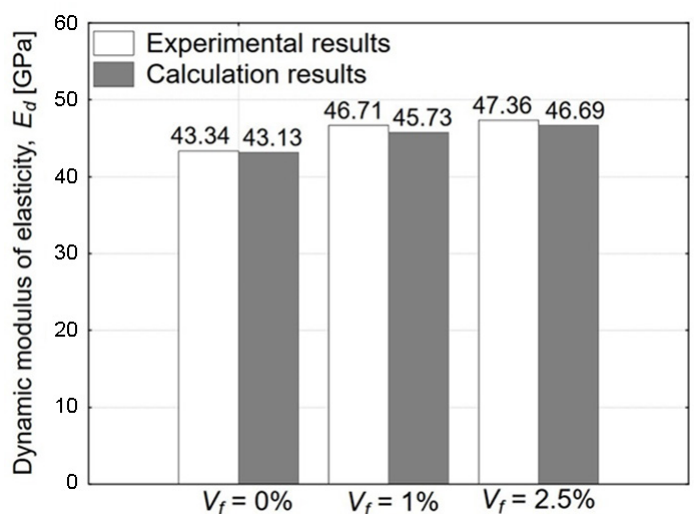

Figure 19. Comparison of values obtained in research and in calculations: dynamic modulus of elasticity $E_{d}$ of tested FRCC

is not effective. When comparing the properties of tested FRCC with the properties of ordinary concrete, it was concluded that the tested composite can be used for making thin-wall construction elements, i.e. industrial floors, plates, covers or construction of tunnels.

\section{Notations}

\section{Variables and functions}

A - cross-sectional area of beam;

$b$ - width of beam;

$d F$ - diameter of fibre;

$E_{d}$ - dynamic modulus of elasticity;

$f_{c, \text { cube }}$ - compressive strength;

$f_{t, s p l}$ - splitting tensile strength;

$f_{\text {tors }}$ - frequency of natural vibrations;

$G_{d}$ - dynamic shear modulus;

$h$ - height of beam;

I - amperage;

$k_{i}$ - coefficient dependant on the type of vibrations;

$l$ - length of beam;

$l_{f}$ - length of fibre;

$m$ - mass of beam;

$r$ - correlation coefficient;

$R$ - coefficient dependant on the dimensions of the beam cross section $b$ and $h$;

$S$ - Abrasion resistance;

$t$ - time of shrinkage;

$V$ - ultrasonic wave velocity;

$V_{f}$ - fibre volume fracture;

w/c - water/cement ratio;

$\alpha-$ level of significance (statistical parameter);

$\lambda$ - slenderness ratio;

$\varepsilon_{\mathrm{s}}$ - shrinkage;

$\rho$ - apparent density;

$v$ - tolerance (statistical parameter).

\section{Abbreviations}

FRCC - fibre reinforced cementitious composite; LS - limit state.

\section{References}

Al-Harthy, A. S.; Halim, M. A.; Taha, R.; Al-Jabri, K. S. 2007. The properties of concrete made with fine dune sand, Construction and Building Materials 21(8): 1803-1808.

https://doi.org/10.1016/j.conbuildmat.2006.05.053

Bae, B.-I.; Chung, J.-H.; Choi, H.-K.; Jung, H.-S.; Choi, C.-S. 2018. Experimental study on the cyclic behavior of steel fiber reinforced high strength concrete columns and evaluation of shear strength, Engineering Structures 157: 250-267. https://doi.org/10.1016/j.engstruct.2017.11.072

Balanji, E. K. Z.; Sheikh, M. N.; Hadi, M. N. S. 2017. Behaviour of high strength concrete reinforced with different types of steel fibres, Australian Journal of Structural Engineering 18(4): 254-261. https://doi.org/10.1080/13287982.2017.1396871

Benoa, J.; Hilara, M. 2013. Steel fibre reinforce concrete for tunnel lining - verification by extensive laboratory testing and numerical modelling, Acta Polytechnica 53(4): 329-337.

Domski, J. 2016. A blurred border between ordinary concrete and SFRC, Construction and Building Materials 112: 247-252. https://doi.org/10.1016/j.conbuildmat.2016.02.205

Domski, J.; Głodkowska, W. 2017. Selected mechanical properties analysis of fibrous composites made on the basis of fine waste aggregate, Annual Set the Environment Protection 19: 81-95.

EN 12390-3:2009 Testing hardened concrete. Compressive strength of test specimens. European standard, 2009.

EN 12390-6:2009 Testing hardened concrete. Tensile splitting strength of test specimens. European standard, 2009.

EN 12390-7:2000 Testing hardened concrete. Density of hardened concrete. European standard, 2000.

Gholamhoseini, A.; Khanlou, A.; MacRae, G.; Scott, A.; Hicks, S.; Leon, R. 2016. An experimental study on strength and serviceability of reinforced and steel fibre reinforced concrete (SFRC) continuous composite slabs, Engineering Structures 114: 171-180. https://doi.org/10.1016/j.engstruct.2016.02.010

Głodkowska, W.; Kobaka, J. 2009. Application of waste sands for making industrial floors, Rocznik Ochrona Srodowiska 11(1).

Głodkowska, W.; Kobaka, J. 2012. The model of brittle matrix composites for distribution of steel fibres, Journal of Civil Engineering and Management 18(1): 145-150. https://doi.org/10.3846/13923730.2012.657405

Głodkowska, W.; Laskowska-Bury, J. 2015. Waste sands as a valuable aggregates to produce fibre-composites, Rocznik Ochrona Srodowiska 17: 507-525.

Hendriks, C. F.; Janssen, G. M. T. 2003. Use of recycled materials in constructions, Materials and Structures 36(263): 604-608. https://doi.org/10.1007/BF02483280

Hoła, J.; Schabowicz, K. 2010. State-of-the-art non-destructive methods for diagnostic testing of building structures - anticipated development trends, Archives of Civil and Mechanical Engineering 10(3): 5-18.

https://doi.org/10.1016/S1644-9665(12)60133-2

Kim, W.; Kim, J.; Kwak, Y.-K. 2016. Evaluation of flexural strength prediction of reinforced concrete beams with steel fibres, Journal of Structural Integrity and Maintenance 1(4): 156-166. https://doi.org/10.1080/24705314.2016.1240522

Lataste, J. F.; Behloul, M.; Breysse, D. 2008. Characterisation of fibres distribution in a steel fibre reinforced concrete with electrical resistivity measurements, NDT and E International 41(8): 638-647. https://doi.org/10.1016/j.ndteint.2008.03.008

Lee, D.-J. 2018. Optimal fiber distribution for tensile properties of injection molded composite, Advanced Composite Materials 27(3): 279-295.

https://doi.org/10.1080/09243046.2017.1405601 
Li, J.; Wu, C.; Hao, H.; Su, Y.; Liu, Z. 2016. Blast resistance of concrete slab reinforced with high performance fibre material, Journal of Structural Integrity and Maintenance 1(2): 51-59. https://doi.org/10.1080/24705314.2016.1179496

Lusis, V.; Krasnikovs, A.; Kononova, O.; Lapsa, V.-A.; Stonys, R.; Macanovskis, A.; Lukasenoks, A. 2017. Effect of short fibers orientation on mechanical properties of composite material - fiber reinforced concrete, Journal of Civil Engineering and Management 23(8): 1091-1099. https://doi.org/10.3846/13923730.2017.1381643

Mahmod, M.; Hanoon, A. N.; Abed, H. J. 2018. Flexural behavior of self-compacting concrete beams strengthened with steel fiber reinforcement, Journal of Building Engineering 16: 228-237. https://doi.org/10.1016/j.jobe.2018.01.006

Maidl, B. 1995. Steel fibre reinforced concrete. Ernst \& Sohn.

Meng, G.; Gao, B.; Zhou, J.; Cao, G.; Zhang, Q. 2016. Experimental investigation of the mechanical behavior of the steel fiber reinforced concrete tunnel segment, Construction and Building Materials 126: 98-107.

https://doi.org/10.1016/j.conbuildmat.2016.09.028

Meyer, C. 2009. The greening of the concrete industry, Cement and Concrete Composites 31(8): 601-605.

https://doi.org/10.1016/j.cemconcomp.2008.12.010

Pinter, P.; Dietrich, S.; Bertram, B.; Kehrer, L.; Elsner, P.; Weidenmann, K. A. 2018. Comparison and error estimation of $3 \mathrm{D}$ fibre orientation analysis of computed tomography image data for fibre reinforced composites, NDT \& E International 95: 26-35. https://doi.org/10.1016/j.ndteint.2018.01.001

PN-B-04111:1984. Materiały kamienne - Oznaczanie ścieralności na tarczy Boehmego. Polish standard, 1984.

Soares, D.; De Brito, J.; Ferreira, J.; Pacheco, J. 2014. In situ materials characterization of full-scale recycled aggregates concrete structures, Construction and Building Materials 71: 237-245. https://doi.org/10.1016/j.conbuildmat.2014.08.025

Sukontasukkul, P.; Pomchiengpin, W.; Songpiriyakij, S. 2010. Post-crack (or post-peak) flexural response and toughness of fiber reinforced concrete after exposure to high temperature, Construction and Building Materials 24(10): 1967-1974. https://doi.org/10.1016/j.conbuildmat.2010.04.003

Teng, T.-L.; Chu, Y.-A.; Chang, F.-A.; Shen, B.-C.; Cheng, D.-S. 2008. Development and validation of numerical model of steel fiber reinforced concrete for high-velocity impact, Computational Materials Science 42(1): 90-99. https://doi.org/10.1016/j.commatsci.2007.06.013

Ulsen, C.; Kahn, H.; Hawlitschek, G.; Masini, E. A.; Angulo, S. C. 2013. Separability studies of construction and demolition waste recycled sand, Waste Management 33(3): 656-662. https://doi.org/10.1016/j.wasman.2012.06.018

Uygunoğlu, T. 2008. Investigation of microstructure and flexural behavior of steel-fiber reinforced concrete, Materials and Structures 41(8): 1441-1449. https://doi.org/10.1617/s11527-007-9341-y

Wang, Z. L.; Liu, Y. S.; Shen, R. F. 2008. Stress-strain relationship of steel fiber-reinforced concrete under dynamic compression, Construction and Building Materials 22(5): 811-819. https://doi.org/10.1016/j.conbuildmat.2007.01.005

Wang, Z. L.; Wu, L. P.; Wang, J. G. 2010. A study of constitutive relation and dynamic failure for SFRC in compression, Construction and Building Materials 24(8): 1358-1363. https://doi.org/10.1016/j.conbuildmat.2009.12.038

Weiler, B.; Grosse, C. 1995. Elastische Parameter - ihre dynamische Messung und Berechnung [Elastic constants - their dynamic measurement and calculation], Otto Graf Journal 6: 1-16.
Yap, S. P.; Alengaram, U. J.; Jumaat, M. Z. 2016. The effect of aspect ratio and volume fraction on mechanical properties of steel fibre-reinforced oil palm shell concrete, Journal of Civil Engineering and Management 22(2): 168-177. https://doi.org/10.3846/13923730.2014.897970

Yazıcı, Ş.; İnan, G.; Tabak, V. 2007. Effect of aspect ratio and volume fraction of steel fiber on the mechanical properties of SFRC, Construction and Building Materials 21(6): 1250-1253. https://doi.org/10.1016/j.conbuildmat.2006.05.025

Zhang, Y.; Dias-da-Costa, D. 2017. Seismic vulnerability of multi-span continuous girder bridges with steel fibre reinforced concrete columns, Engineering Structures 150: 451-464. https://doi.org/10.1016/j.engstruct.2017.07.053 